\title{
USO DAS TERRAS E SUAS POTENCIALIDADES NA PRESTAÇÃO DOS SERVIÇOS AMBIENTAIS
}

\author{
Lucas Emanuel Servidoni $^{(\mathrm{a})}$, Joaquim Ernesto Bernardes Ayer ${ }^{(\mathrm{b})}$, Marx Leandro Naves Silva $^{(\mathrm{c})}$, \\ Ronaldo Luiz Mincato ${ }^{(\mathrm{d})}$ \\ (a) Instituto de Ciências da Natureza, Universidade Federal de Alfenas - MG, lucas_servidoni@hotmail.com \\ (b) Instituto de Geociências, Universidade Estadual de Campinas, joaquimayer@ige.unicamp.br \\ (c) Departamento de Ciência do Solo, Universidade Federal de Lavras, marx @ dcs.ufla.br \\ (d) Instituto de Ciências da Natureza, Universidade Federal de Alfenas - MG, ronaldo.mincato@unifal-mg.edu.br
}

Eixo: USO E OCUPAÇÃO DAS TERRAS E LEGISLAÇÃO AMBIENTAL

\begin{abstract}
Resumo/
Os serviços ambientais advêm das propriedades e da capacidade produtiva dos recursos naturais e beneficiam os ecossistemas e a sociedade. Estes benefícios são necessários para manter o meio ambiente ecologicamente equilibrado e sustentável. A Sub-bacia hidrográfica do Córrego Pedra Branca, no Município de Alfenas - MG, apresenta carência de manejos conservacionistas no uso e ocupação do solo, que se caracteriza basicamente pelo descumprimento da legislação ambiental, que compromete a prestação dos serviços ambientais e ecossistêmicos dos recursos naturais. Assim, o objetivo deste trabalho é propor a implantação de corredores ecológicos nas áreas de proteção ambiental e de reserva legal da sub-bacia para favorecer a prestação dos serviços ambientais e ecossistêmicos e promover a sustentabilidade socioeconômica e ambiental da área a partir do planejamento territorial com base nas tecnologias de geoprocessamento.
\end{abstract}

Palavras chave: ArcGIS, Landsat 8, Corredores Ecológicos.

\section{Introdução}

Os serviços ambientais advêm das propriedades e da capacidade produtiva dos recursos naturais e beneficiam os ecossistemas e a sociedade. Estes benefícios são de essenciais para manter o meio ambiente ecologicamente equilibrado e sustentável. Dentre os benefícios estão a proteção do equilíbrio hidrológico, a prevenção de deslizamentos de massas e o controle da erosão promovido pelas matas nativas e a polinização de plantas por insetos, entre outros. Parron et al. (2015) apontam a importância dos serviços ambientais para a proteção e manutenção da biodiversidade e do equilíbrio ecológico do planeta. A expansão das atividades agropecuárias sem práticas de manejo conservacionistas acentua os processos de degradação do meio ambiente e compromete a prestação dos serviços ambientais (SERVIDONI et al., 2016).

As geotecnologias permitiram um aumento da produtividade das pesquisas relacionadas à evolução do uso e ocupação da terra devido às facilidades de rapidez e precisão e baixo custo no tratamento e interpretação 
de uma grande quantidade de dados georreferenciados. Tal desenvolvimento contribui para a melhoria dos estudos que envolvem a qualidade e conservação do meio ambiente. Neste cenário, o geoprocessamento é essencial para a produção de informações estratégicas para a tomada de decisão e contribui para melhorar o planejamento e a gestão territorial (OLIVETTI et al., 2015).

A harmonia entre os conceitos de serviços ambientais e ecossistêmicos, como a proteção e conservação dos solos e das águas pelas matas nativas, com as aplicações das geotecnologias é possível avaliar a eficácia dos serviços ambientais para a manutenção da sustentabilidade socioeconômica e ambiental. Para tanto foram utilizados os limiares mínimos de 50 hectares de área para garantir a segurança dos serviços ambientais prestados pelos fragmentos de matas nativas (SOS Mata Atlântica e INPE, 2012). Mais ainda, na avaliação dos serviços de polinização de plantas pelos insetos, no bioma Mata Atlântica, McGrefor (1976), Rickets et al. (2004) e Raniero (2013) concluíram que é necessário um limiar mínimo de 25\% em área de matas nativas para que haja prestação satisfatória desses serviços.

Neste cenário, os efeitos das práticas agropecuárias nos solos são salientados por Dale e Polasky (2007), que apontam que as técnicas de manejo conservacionistas, especialmente a produção de fertilizantes orgânicos pelos resíduos da agropecuária, além de promover o aumento da produtividade na agricultura, adiciona valor de mercado aos produtos. Por outro lado, tais autores destacam ainda que os usos de práticas agropecuárias convencionais aumentam as taxas de erosão e afetam negativamente os serviços ecossistêmicos processados pelos solos.

Os corredores ecológicos são uma alternativa sustentável para a restauração e manutenção da biodiversidade em sub-bacias hidrográficas (Parron et al., 2015), pois conectam os fragmentos de mata nativa em uma determinada área, promovendo a sustentabilidade ambiental das espécies e a conservação dos recursos naturais. Ao favorecer o fluxo gênico dentro do fragmento, os corredores ecológicos aumentam a variabilidade genética e consequentemente melhoram a qualidade da biodiversidade do bioma mata atlântica, bioma intensamente afetado pelas atividades agropecuárias.

A análise de imagens de satélite permitiu mapear o uso do solo e avaliar se as áreas destinadas a matas nativas em uma região estão em acordo com os limiares mínimos para que os serviços ambientais de conservação do solo e da água e polinização de plantas por insetos estejam em níveis sustentáveis. Sendo assim, o presente estudo realizou o mapeamento do uso do solo na sub-bacia hidrográfica do Córrego Pedra Branca, em Alfenas, sul de Minas Gerais, delimitando e quantificando as áreas destinadas as matas nativas e aos corredores ecológicos, avaliando se os fragmentos florestais atendem aos requisitos 
estabelecidos pelo SOS Mata Atlântica e INPE (2012). Posteriormente foi elaborado a proposta de criação de corredores ecológicos levando em consideração a forma e proximidade entre os fragmentos.

\section{Materiais e Métodos}

A área de estudo compreende a sub-bacia hidrográfica do Córrego Pedra Branca no município de Alfenas, Sul de Minas Gerais entre as coordenas geográficas $21^{\circ} 20^{\prime}$ até $21^{\circ} 00^{\prime}$ Sul e $45^{\circ} 55^{\prime}$ até $46^{\circ} 00^{\prime}$ Oeste (Figura 1). Com 2.642 ha, as faixas altimétricas se encontram entre 780 e $920 \mathrm{~m}$. A geologia local é composta basicamente por granito gnaisses e charnockitos (HASUY, 2010). O clima, segundo Köppen, é classificado como Tropical Mesotérmico ou Tropical de Altitude (SPAROVEK et al., 2007).

A imagem utilizada para classificação do uso do solo foi obtida pelo satélite Landsat- 8 Sensor Operational Imager - OLI em 14 de Março de 2015. Esta imagem é disponibilizada gratuitamente pelo Instituto Nacional de Pesquisas Espaciais. A partir dela foi criada uma composição colorida com resolução espacial de $30 \mathrm{~m}$ e resolução radiométrica de 16 bits. A classificação foi feita de forma manual com o Software ArcGIS 10.2.1 e os parâmetros adotados para classificação da imagem foram: textura, cor e rugosidade. Trabalhos de campo foram realizados para checagem e correções dos erros de classificação.
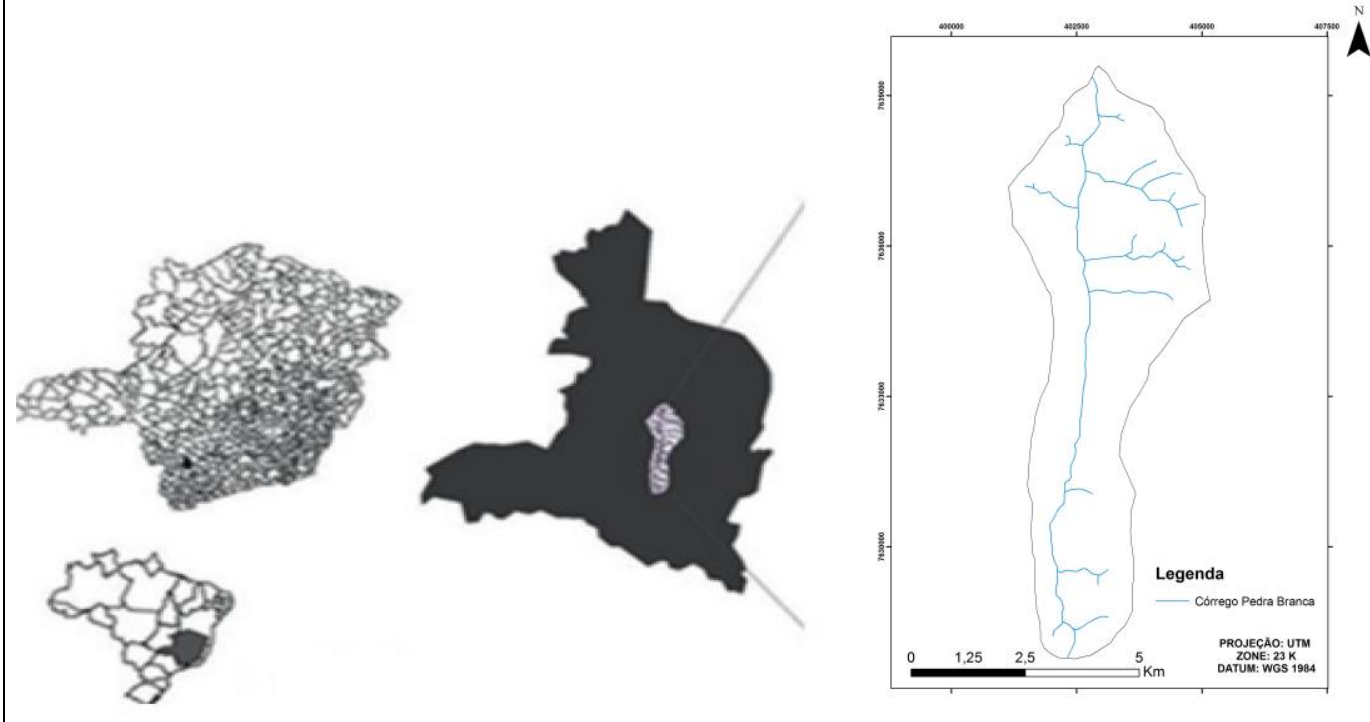

Figura 1 - área de estudo com destaque para a hidrografia da Sub-bacia hidrográfica do Córrego Pedra Branca. Fonte: Adaptado de Ayer et al. (2015).

Posteriormente foi calculado, utilizando a ferramenta Map calculator do ArcGIS 10.2, a área total em ha dos fragmentos de mata nativa na sub-bacia e seus respectivos valores em porcentagem. $\mathrm{O}$ cruzamento destas informações com as recomendações do SOS Mata Atlântica e o INPE (2012) permitiu averiguar se os serviços ambientais de conservação do solo e da água estavam sendo prestados de forma satisfatória. 


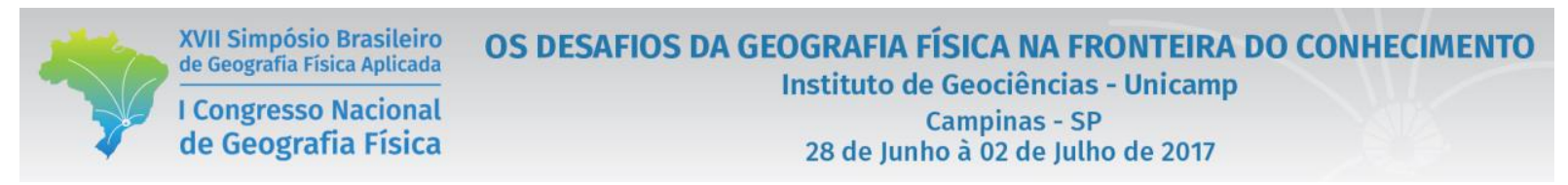

Os dados de McGrefor (1976), Rickets et al. (2007) e Raniero (2013) permitiram checar se os serviços de polinização estavam adequados.

A partir deste mapeamento e levando em consideração a distribuição da várzea, da área de preservação permanente (APP) e do tamanho, forma e distribuição dos fragmentos florestais, foi confeccionado a proposta de recuperação da mata ciliar do Córrego Pedra Branca e criação de corredor ecológico para manutenção da biodiversidade e conservação dos recursos naturais. Para tal foi utilizado a ferramenta buffer do ArcGIS 10.2.1.

\section{Resultados e Discussões}

A classificação manual das imagens do satélite Landsat permitiu identificar os usos do solo para o ano de 2015. Os usos classificados foram: café, cana-de-açúcar, eucalipto, mata nativa, solo exposto, área urbana, várzea e pastagem. A tabela 1 apresenta as classes de uso do solo e seus respectivos valores de área em há e porcentagem.

Os resultados obtidos no mapeamento do uso do solo nas APP da sub-bacia hidrográfica do Córrego Pedra Branca por Servidoni et al. (2016) apontam que 60\% das APP estão de acordo com a legislação ambiental. Porém, $40 \%$ estão ocupadas por culturas agrícolas de alto impacto deletério sobre o solo e a água. As APP de rios em bacias hidrográficas têm um papel fundamental na manutenção do equilíbrio hidrológico de sistemas fluviais.

Tabela I - Uso do solo na sub-bacia hidrográfica do Córrego Pedra Branca em hectares (ha) e porcentagem (\%) em 2015.

\begin{tabular}{|c|c|c|}
\hline \multirow{2}{*}{ Uso do solo } & \multicolumn{2}{|c|}{ 2015 } \\
\cline { 2 - 3 } & ha & 4,00 \\
\hline Café & 105,00 & 0,14 \\
\hline Cana-de-açúcar & 4,00 & 6,40 \\
\hline Eucalipto & 169,00 & 11,00 \\
\hline Mata nativa & 290,00 & 4,94 \\
\hline Solo exposto & 130,00 & 21,62 \\
\hline Área urbana & 571,00 & 7,50 \\
\hline Várzea & 198,00 & 44,40 \\
\hline Pastagem & 1173,00 & \\
\hline
\end{tabular}

O uso ilegal do solo associado à baixa presença de mata nativa nas várzeas e APP aumentam a produção de sedimentos provocando o assoreamento da várzea e do canal fluvial do Córrego Pedra Branca. O 
exutório da sub-bacia desemboca no Córrego da Ferradura que desagua no reservatório de furnas prejudicando também a produção de energia elétrica.

Em mapeamento das perdas de solo pela erosão hídrica na área de estudo, Ayer et al. (2015) mostraram que os usos do solo que mais contribuem para a produção de sedimentos foram as pastagens e a cultura do eucalipto. Segundo estes autores, a contribuição para produção de sedimentos para estes usos foram $51,30 \%$ e $21,80 \%$, respectivamente. Parte dos povoamentos de eucaliptos e das pastagens estão em APP, prejudicando consideravelmente a qualidade dos serviços ambientais de conservação prestados pelas matas ciliares.

Para que os serviços ambientais sejam prestados em níveis satisfatórios é necessário que os fragmentos de mata nativa possuam ao menos 50 ha. A tabela 1 demonstra que as áreas de mata nativa somam 290 ha. Todavia, esses 290 ha não estão conectados e, portanto, os fragmentos florestais presentes na sub-bacia não alcançam o limiar mínimo de 50 ha. Esse fato, compromete a prestação dos serviços ambientais na sub-bacia do Pedra Branca (SOS Mata Atlântica e INPE, 2012). A figura 2 ilustra a distribuição espacial dos usos do solo na área de estudo. 


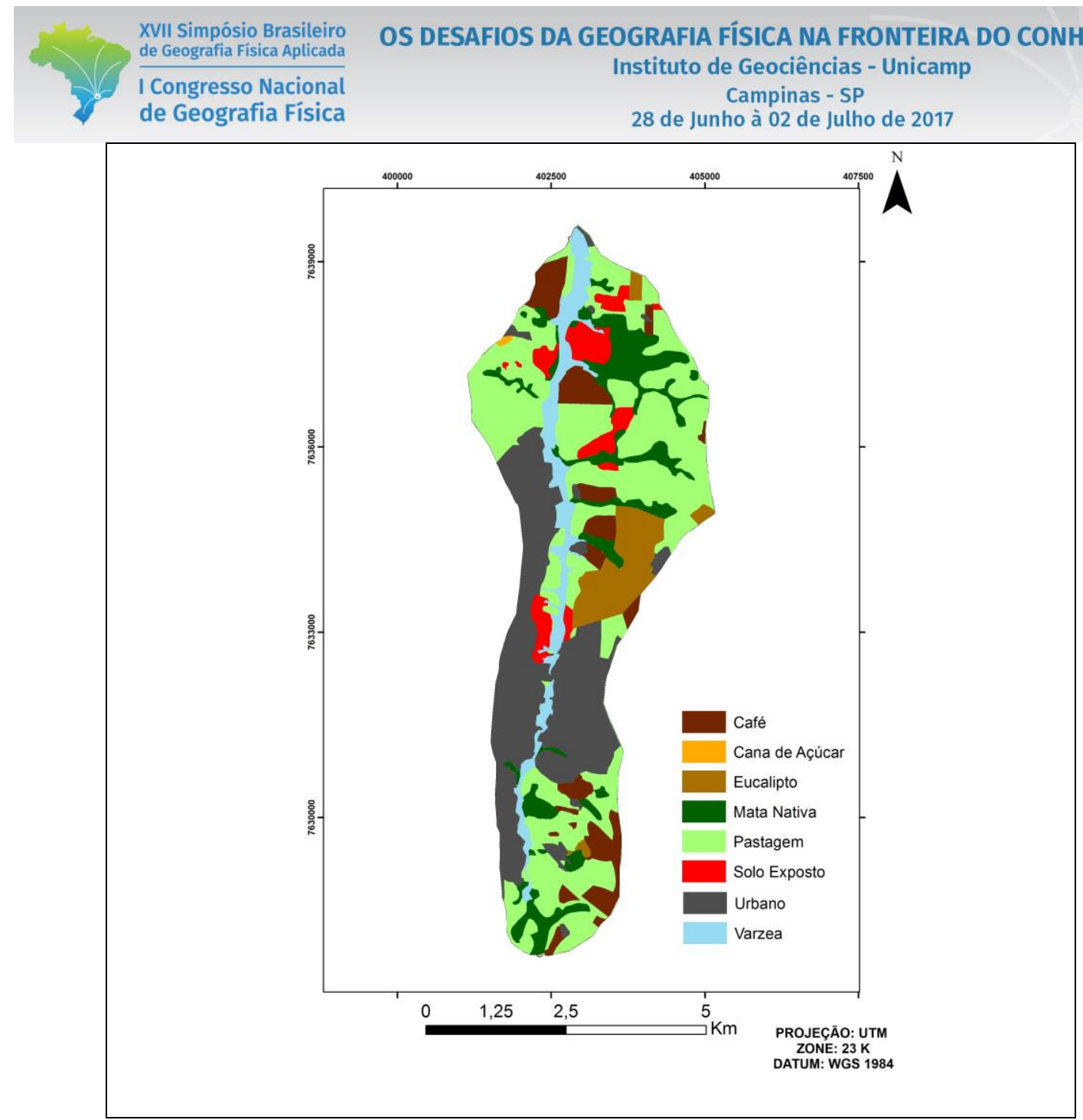

Figura 2 - distribuição espacial do uso solo na sub-bacia hidrográfica do Córrego Pedra Branca no ano de 2015.

De acordo com McGrefor (1976) e Rickets et al. (2007), os serviços de polinização das abelhas são responsáveis por $70 \%$ da produtividade agrícola mundial. Os estudos de Raniero (2013) apontam que na região onde está inserida a sub-bacia hidrográfica do Pedra Branca é necessário o mínimo de 25\% de matas nativas para que os serviços de polinização ocorram de forma satisfatória. O mapeamento do uso do solo demonstrou que as áreas de mata nativa ocupam apenas $11 \%$ da área, um valor muito abaixo do limiar mínimo (Figura 3). Dessa forma, os serviços ambientais de polinização e conservação do solo e da água pelas matas fica comprometido devido à fragmentação da paisagem, falta de APP e de manejos conservacionistas e de consciência ambiental. 

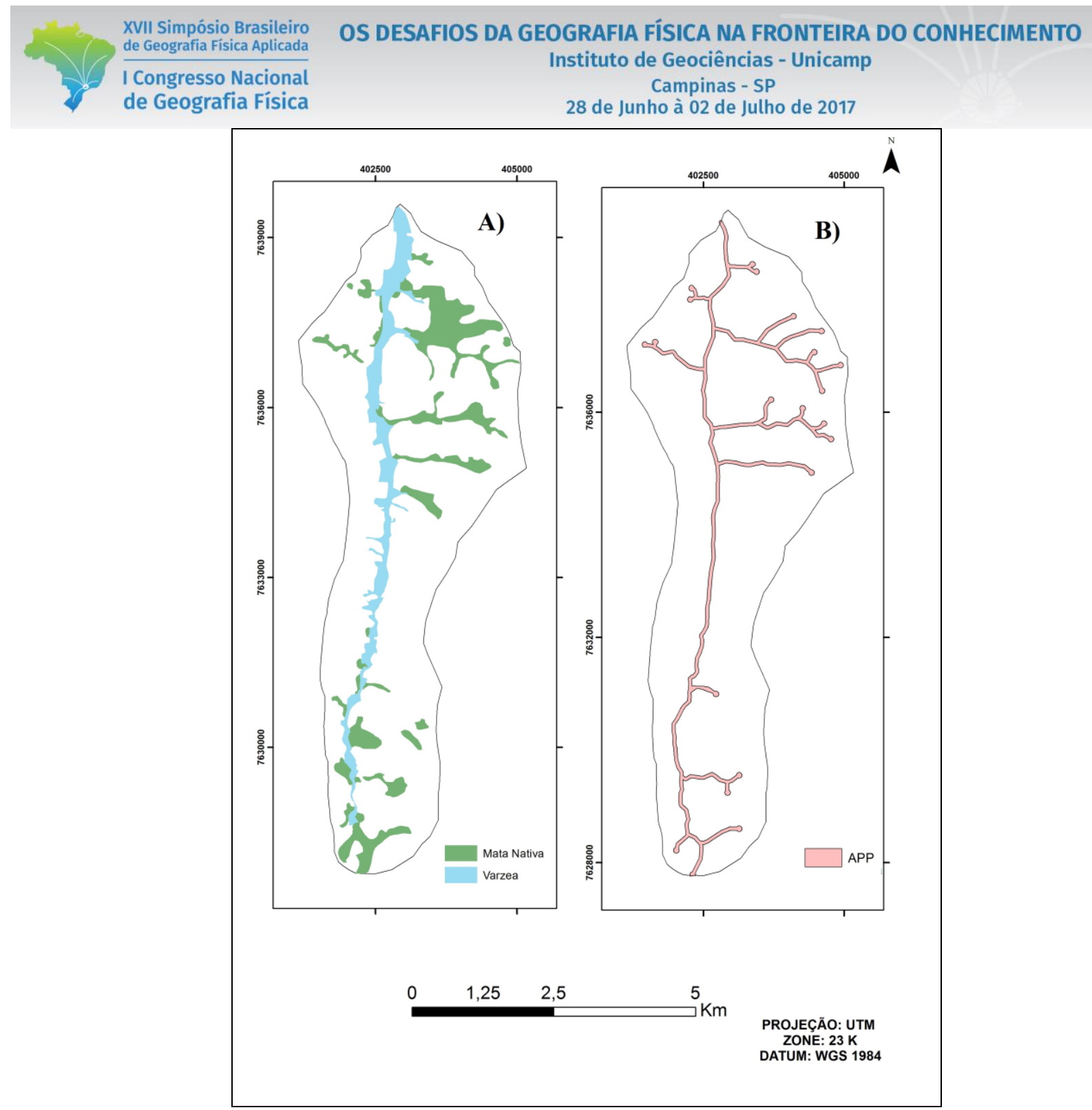

Figura 3 - A) Distribuição espacial das áreas de preservação permanente em torno de rios e nascentes. B)

Distribuição espacial dos fragmentos de mata nativa e da várzea do Córrego Pedra Branca.

A partir da Figura 3 é possível comparar a distribuição espacial das APP com as áreas de várzea do Córrego Pedra Branca e os fragmentos de Matas Nativas. É necessário estabelecer uma área de matas nativas maior do que a prevista na legislação, abrangendo toda a várzea do córrego para proteger e conservar, dessa forma, o solo e a água.

Vale lembrar que além destes serviços ecossistêmicos, a cidade de Alfenas surgiu nesta sub-bacia e ainda possui a maior parte de sua expansão urbana dentro da mesma. O que torna necessário um ordenamento territorial planejado, que vise a garantia da melhoria da qualidade de vida nos centros urbanos, visto que a preservação e recuperação destes recursos, favorece o equilíbrio climático local, reduzindo as oscilações extremas de temperatura, a filtragem do ar e dos ruídos, o controle de pragas, além de possibilitar a integração do homem ao meio ambiente, favorecendo um equilíbrio espiritual e psicológico. Para tanto, é 
necessário conectar os fragmentos florestais e reestabelecer a mata nativa na área de várzea do Córrego Pedra Branca, conforme proposto na Figura 4.

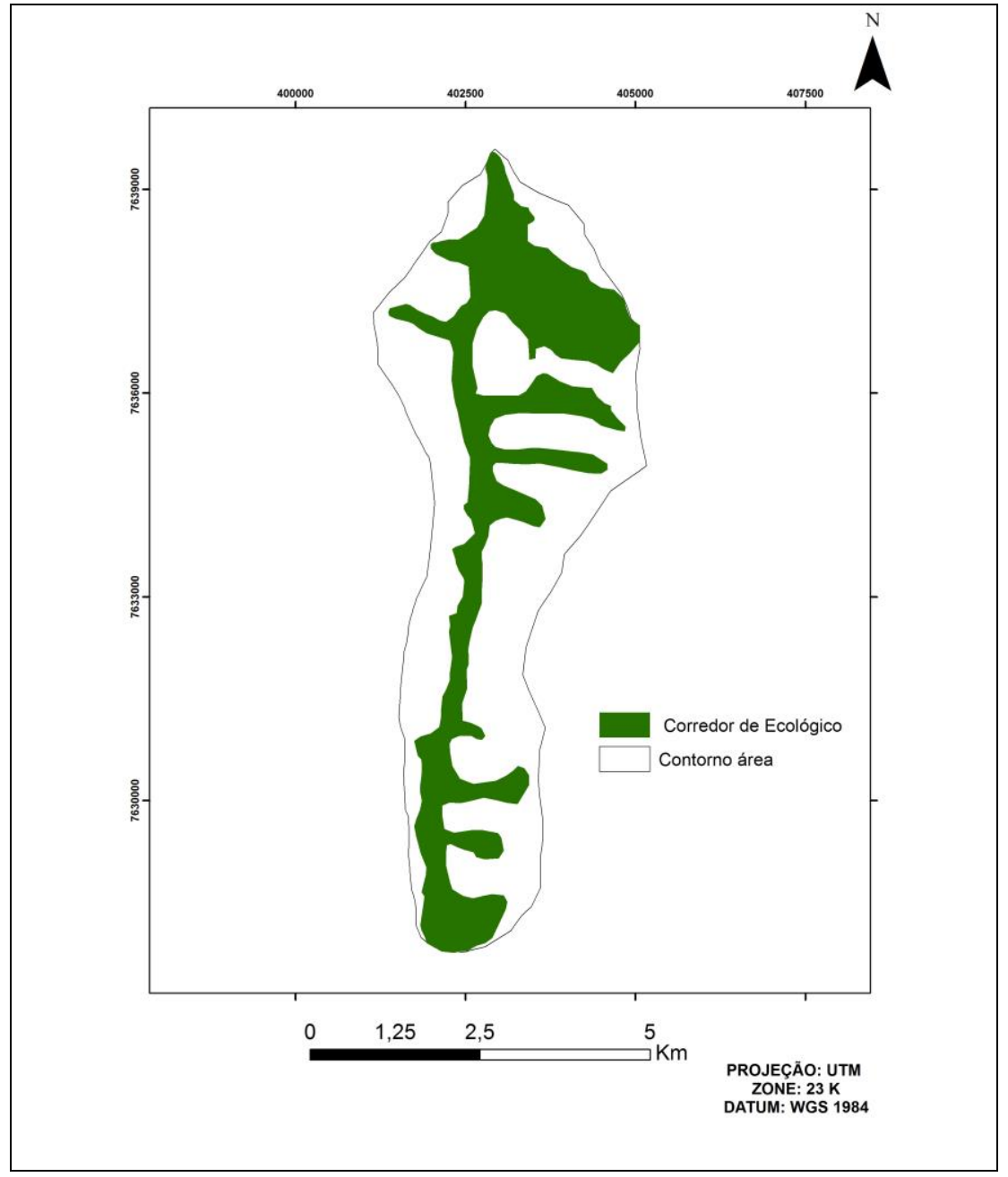

Figura 4 - Proposta de implantação de corredor ecológico na área da Sub-bacia Hidrográfica do Córrego

$$
\text { Pedra Branca - Alfenas - MG. }
$$

Os corredores ecológicos, segundo Parron et al. (2015), são áreas que possuem ecossistemas florestais biologicamente prioritários e viáveis para a conservação da biodiversidade. Por estar inserido em uma região de transição entre os biomas mata atlântica e cerrado, ambos ameaçados pela expansão urbana e pelas atividades agropecuárias, é imperativo a recuperação das matas ciliares do Córrego Pedra Branca, com o reestabelecimento de sua vegetação nativa, considerando a legislação, os aspectos hidrogeológicos e a forma e distribuição dos fragmentos florestais remanescentes.

A consolidação do corredor ecológico aumentaria a quantidade de matas nativas na sub-bacia do Pedra Branca de $11 \%$ para 30\% abrangendo uma área contínua de 790 ha compreendendo toda a várzea do 
córrego. Com $30 \%$ de mata nativa na sub-bacia, os serviços de polinização estariam assegurados como apontam McGrefor (1976), Rickets et al. (2007) e Raniero (2013).

Para tanto, é necessário a criação de políticas públicas que conscientizem e incentivem a recuperação de áreas degradadas, com atrelamento de financiamentos a propriedades que contribuam para a manutenção do equilíbrio ecossistêmico. Neste cenário, chama atenção que o atual código florestal (Brasil, 2012), se contrapõe aos principais resultados das pesquisas internacionais, sobre aumento da produtividade agropecuária como demonstram Tilman et al. (2002) e Parron et al. (2015)

A consolidação do corredor ecológico poderá contribuir para controlar as perdas de solo na sub-bacia hidrográfica e impedir impactos ambientais como o assoreamento de rios, lagos e reservatórios, assegurando um equilíbrio hidrossedimentológico na área. A biodiversidade também se beneficiaria com a implantação do corredor. Com fragmentos florestais maiores e contínuos mais espécies poderão utilizar os recursos disponíveis e estas mesmos espécies estará menos sujeito a predação, pois não precisa se locomover entre fragmentos de mata nativa.

\section{Conclusões}

Os solos da Sub-bacia do Córrego Pedra Branca são pobres em matéria orgânica e apresentam baixa fertilidade natural e são muito propensos a processos erosivos e pouco indicados para culturas temporárias.

A adoção de técnicas de manejo conservacionistas, como por exemplo plantio direto e em nível, pode contribuir para o aumento da produtividade das atividades agropecuárias.

A histórica fragmentação da paisagem em conjunto com a ausência de manejos conservacionistas nas atividades agropecuárias prejudica a oferta dos serviços ecossistêmicos e ambientais, além de aumentar os processos de degradação dos solos pela erosão hídrica.

A utilização das Geotecnologias permitiu identificar áreas ilegais de acordo com a atual legislação ambiental brasileira, permitindo elaborar um plano de recuperação da sub-bacia do Córrego Pedra Branca. A consolidação de corredores ecológicos aumentará a área de mata nativa de $11 \%$ para 30\% abrangendo uma área contínua de 790 ha, assegurando a prestação de serviços ambientais.

\section{Agradecimentos}

Agradecimentos à CAPES, pela bolsa de estudos. 


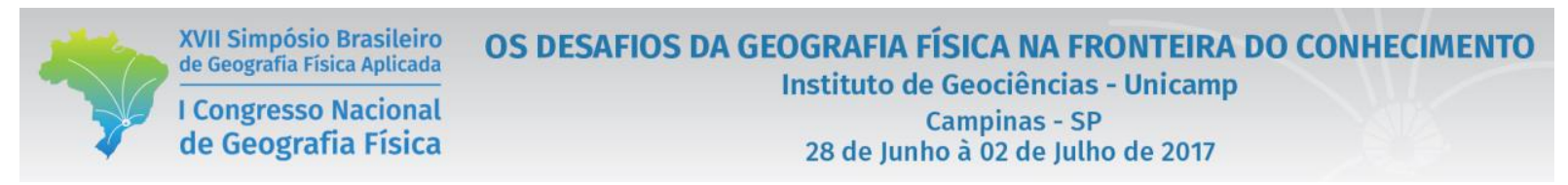

\section{Bibliografia}

AYER, J. E. B.; OLIVETTI, D.; MINCATO. R. L.; SILVA, M. L.N. Erosão hídrica em Latossolos vermelhos distróficos. Goiânia: Pesquisa Agropecuária Tropical, v.45, n.2, p.180-191, 2015.

DALE, V. H.; POLASKY, S., Measures of the effects of agricultural practices on ecosystem services. Amsterdan: Ecological Economics, v.64, n.2, p.286-296. 2007.

HASUI, Y. A grande colisão pré-cambriana do Sudeste Brasileira e a estruturação regional. São Paulo: Revista Geociências, v. 20, n. 2, p. 141-169, 2010.

MACGREGOR, S.R. Insect pollination of cultivated crop plants. Washington: Agriculture Handbook, $1^{\circ} \mathrm{Ed}, 1976$.

PARRON, L.M.; GÁRCIA, J.R.; DE OLIVEIRA, E.B.; BROWN, G.; PRADO, R.B. Serviços ambientais em sistemas agrícolas e florestais do Bioma Mata Atlântica. Brasília: Empresa de Pesquisa Agropecuária, 370p. 2015.

RANIERO M. O efeito da paisagem na subtribo de abelhas Euglossina (Hymenoptera: Apidae). Dissertação de Mestrado em Ecologia e Tecnologia Ambiental, UNIFAL-MG, Alfenas, 2013.

RICKETTS, T.H., DAILY, G.C., HERLICH, P.R., MICHENER, C.D., Economic value of tropical forest to coffee production. Proceedings of the National Academy of Sciences of the United States of America v.101, p.12579-12582, 2004.

SERVIDONI, L.E.; AYER, J.E.B.; SILVA, M.L.N.; SPALEVIC, V.; MINCATO, R.L. Land use capacity and environment services. Recife: Revista Brasileira de Geografia Física, v.9, n.6, p.17121724, 2016.

SPAROVEK, G.; VAN LIER, Q.J.; DOURATO NETO, D. Computer assisted Köppen climate classification: case study for Brazil. Chichester: International Journal Climatology, v.27, n.2, p.257-266, 2007.

OLIVETTI, D.; MINCATO, R.L.; AYER, J.E.B.; SILVA, M.L.N.; CURI, N. Spatial and temporal modeling of water erosion in dystrophic red latosol (oxisol) used for farming and cattle raising activities in a sub-basin in the South of Minas Gerais. Lavras: Revista Ciência Agrotecnologia, v.39, n.1, p.58-67, 2015.

SOS MATA ATLÂNTICA; INSTITUTO NACIONAL DE PESQUISAS ESPACIAIS - INPE. Atlas dos Municípios da Mata Atlântica - período 2011-2012. São José dos Campos, 2013. 


\begin{tabular}{|c|c|}
\hline $\begin{array}{l}\text { XVII Simpósio Brasileiro } \\
\text { de Geografia Fisica Aplicada }\end{array}$ & $\begin{array}{c}\text { OS DESAFIOS DA GEOGRAFIA FÍSICA NA FRONTEIRA DO CONHECIMENTO } \\
\text { Instituto de Geociências - Unicamp }\end{array}$ \\
\hline $\begin{array}{l}\text { I Congresso Nacional } \\
\text { de Geografia Física }\end{array}$ & $\begin{array}{l}\text { Campinas - SP } \\
28 \text { de Junho à } 02 \text { de Julho de } 2017\end{array}$ \\
\hline
\end{tabular}

TILMAN, D.; CASSMAN, K.G.; MATSON, P.A.; NAYLOR, R.; POLASKY, S. Agricultural sustainability and intensive production pratices. Londre: Nature, vol. 418, August, 2002. 